\title{
Effect of Tropical Fruit Juices on Surface Roughness of Tooth Coloured Restorative Materials
}

\author{
Siti Musfirah Binti Mustain, Aws Hashim Alkadhim*, Faizah Abdul Fatah and Azlan Jaafar \\ Faculty of Dentistry, Universiti Sains Islam, Malaysia \\ *Corresponding author: Aws Hashim Alkadhim, Faculty of Dentistry, Universiti Sains Islam Malaysia, Bandar \\ Baru Nilai, 71800 Nilai, Negeri Sembilan, Malaysia, Tel: +60 342892400; E-mail: awshashim@usim.edu.my
}

Received Date: 21 July 2017; Accepted Date: 9 October 2017; Published Date: 31 October 2017

\begin{abstract}
The restorative materials should have the ability to with stand challenging environment such as an acidic environment as the restorative material may be subjected to erosive attack from the low $\mathrm{pH}$ of acidic beverages in the oral cavity. The aim of this study was to investigate the effect of Malaysian fruit juices on the surface roughness. Forty disc shape samples were prepared for each of selected tooth coloured restoration (composite, GIC, RMGIC). The surface roughness before immersion was taken then the samples were immersed in the following storage media: distilled water, pineapple juice, mango juice, and tamarind juice. After time intervals of 1 day, the surface roughness was determined for each individual sample using profilometer. Differences were analysed using SPSS version 21. The results showed all materials were found to have increase in the surface roughness after immersion in the juices. The tamarind juices were shown to pose a greater erosive threat to tooth coloured materials than pineapple and mango. Composite showed to have the highest mean changes is surface roughness compared to GIC and RMGIC. In conclusion, the acidic juices affected the surface roughness of the selected tooth coloured restoration.
\end{abstract}

\section{Keywords}

Erosion; Fruit Juices; Surface Roughness

\section{Introduction}

Individuals these days particularly adolescents and young adults want to eat less and expend more foods grown from the ground $[1,2]$. This incorporates the admission of fruits and juices which are acidic. Acid can be divided into two types, which are strong and weak acid [3]. First are strong acids which are very corrosive and can cause burns on skin, examples of strong acids are hydrochloric acid, nitric acid, and sulfuric acid. Strong acids also known as mineral or inorganic acids. Second are weak acids which are somewhat destructive and typically don't influence skin [4]. The cases of weak acids are acidic corrosive which for the most part in vinegar, citrus extract that are for the most part in citrus organic product juice acid, and tartaric acid. Weak acids are additionally called as characteristic or natural acids $[5,6]$. There are many researches that have been done appeared there is relationship between acidic drinks and tooth surface loss. Tooth surface loss that generally identified with utilization of acidic refreshments is erosion [7]. Erosion is characterized as the procedure whereby the surface of subject is being worn away as the after effect of activity of something that is grating. Then again, dental erosion is characterized as irreversible loss of tooth structure because of chemical disintegration by acids and not as a result of bacterial inception $[8,9]$. There are two reasons for dental erosion, which are extrinsic and intrinsic. Extrinsic causes are usually from acidic sustenance's and beverages, for example, orange juices and sodas. Intrinsic causes are from inside, for example, gastric juices [10]. The most widely recognized reason for disintegration is the consequence of utilization of acidic squeezes and acrid nourishments, for example, pickles [11]. The signs and side effects that can be seen when individuals have dental erosion are smooth, appears like cleaned and rounded teeth. Any restorations show additionally get to be distinctly proud restorations [12]. People presented with dental erosion likewise may grievance of pain or sensitivity during eating or taking cold or hot beverages. They likewise feel delicate to air blow on the teeth [13]. These individuals who got erosion may feel delicate on account of uncovered (exposed) dentinal tubules which cause the dentinal fluid to move along the tubule and trigger the pain sensation [14]. Hence, patients may require restoration later to relieve the pain [15]. Creating a challenging environment in the oral cavity thus, the restorative materials that will be utilized to re-establish the tooth must be able to withstand such difficult condition in the mouth. Regularly utilized restorative materials in the oral cavity are amalgam and dental resins which incorporate composite, glass ionomer cement, resin modified glass ionomer cement and compomer, be that as it may, these days patients begin to select tooth coloured therapeutic materials 
Citation: Mustain SMB, Alkadhim AH, Fatah FA, Jaafar A (2017) Effect of Tropical Fruit Juices on Surface Roughness of Tooth Coloured Restorative Materials. J Dent Sci Res Ther 2017: 26-29. DOI : https://doi.org/10.29199/2637-7055/DSRT.101013.

as they are more aesthetic than amalgam [16]. Composite has the upside of aesthetic and chemically bond to the tooth $[17,18]$. While glass ionomer cement likewise has chemical bonding and fluoride discharging property. Then again, resin modified glass ionomer cement has the mechanical and aesthetic property like composite, and fluoride discharging property like glass ionomer cement. Many studies have been done regarding the effect of acidic fruit juices on tooth coloured restorative materials, however most of the data available were done in Western fruit juices and carbonated drinks. In Malaysia, the fruit juices chosen by the netizen are local fruit juices, however the data about the effect of Malaysian fruit juices on tooth coloured restorative material is limited. Some people may question why this study need to be done as they think that if the fruit juices have similar $\mathrm{pH}$, the effect must be the same, but there is no prove to that statement as different juices have different contents that may affect the dental materials. Besides, as the consumption of acidic drinks nowadays is increasing, more studies are required to investigate this effect. That is why this study was purposed to further investigate the relationship of acidic beverages on dental restorative materials. The aim of this study is to investigate the potential effect of selected tropical fruit juices on different types of tooth colored restorative materials, and to evaluate the changes in surface roughness of selected tooth coloured restorative materials which are composite, glass ionomer cement and resin modified glass ionomer cement after one day immersion in selected Malaysian fruit juices which are pineapple, mango, and tamarind juices, and distilled water as control.

\section{Materials and Methods}

For the methodology of this study, first, initial preparation whereby plastic mould in disc shape was prepared for sample fabrication, $\mathrm{pH}$ for the selected fruit juices which were pineapple (F\&N Fruit Tree (Shah Alam, Malaysia)), mango (F\&N Fruit Tree (Shah Alam, Malaysia)), and tamarind (F\&N Fruit Tree (Shah Alam, Malaysia)) juices was measured and recorded using $\mathrm{pH}$ meter. Then proceeded with sample preparation. A120 samples which include 40 samples for each restorative materials (composite (GC Gradia Direct X (Tokyo, Japan)), glass ionomer cement (GC Fuji IX Extra (Tokyo, Japan)), and resin modified glass ionomer cement (GC Fuji II LC (Tokyo, Japan)) in a disc shape with diameter of $12 \mathrm{~mm}$ and $2 \mathrm{~mm}$ thickness were prepared. The samples were further subdivided into 10 samples each according to the selected juices. The mould with the restorative materials was held between two PVC clear sheets on flat surface and pressed firmly to avoid bubbles and to get smooth surface and not required further grinding and polishing. The composite and resin modified glass ionomer cement were polymerised as per the manufacturer recommendation, while glass ionomer cement was left self-cured. Then the pre-immersion weight was recorded, and followed by pre-immersion surface Roughness (Ra) using stylus surface profilometer (AM BiOS XP100). To measure the surface roughness value, the diamond stylus was moved across the surface of the samples under constant load. After that the samples were placed in the universal bottle $(120 \mathrm{ml})$ with label before immersed in selected fruit juices and kept in the incubator at $37^{\circ} \mathrm{C}$ for one day. Lastly the post-immersion surface roughness was recorded using the same profilometer with same setting.

\section{Statistical Analysis}

The data was analysed using SPSS version 21. This study followed statistical analysis done by previous research related to the topic. We used one way ANOVA at $\mathrm{P}<0.05$ level of significance to compare the mean changes of surface roughness of each or restorative materials after immersion in the juices.

\section{Results}

Composite (GC Gradia Direct X (Tokyo, Japan)) showed the highest mean changes in surface roughness after immersion in the mango juice and record the lowest in distilled water with. While for Glass ionomer Cement (GC Fuji II LC (Tokyo, Japan)), the highest mean changes in surface roughness can be seen after immersion in pineapple juice and lowest changes in distilled water. Resin modified Glass ionomer Cement (GC Fuji II LC (Tokyo, Japan)) showed the highest mean changes in surface roughness following immersion in pineapple juice and record the lowest changes in distilled water as shown in table 1.

\begin{tabular}{|c|c|c|}
\hline Variables & $\begin{array}{c}\text { Surface roughness } \\
\text { (Micrometre) }\end{array}$ & \\
\hline & Baseline & After \\
\hline Mean (SD) & Mean (SD) \\
\hline Composite & & \\
\hline Pineapple juice & $4.00(3.65)$ & $12.29(3.91)$ \\
\hline Mango juice & $3.87(2.49)$ & $12.68(4.50)$ \\
\hline Tamarind juice & $6.78(3.02)$ & $9.58(5.31)$ \\
\hline Distilled water & $5.42(3.36)$ & $5.72(3.39)$ \\
\hline GIC & & \\
\hline Pineapple juice & $6.36(5.42)$ & $11.36(5.05)$ \\
\hline Mango juice & $7.72(5.14)$ & $12.24(6.19)$ \\
\hline Tamarind juice & $9.30(5.88)$ & $13.37(6.62)$ \\
\hline Distilled water & $5.69(4.85)$ & $8.86(4.82)$ \\
\hline RMGIC & & $15.20(5.38)$ \\
\hline Pineapple juice & $6.73(3.59)$ & $13.11(5.11)$ \\
\hline Mango juice & $8.03(5.00)$ & $11.66(5.39)$ \\
\hline Tamarind juice & $8.29(5.00)$ & $8.91(4.76)$ \\
\hline Distilled water & $8.12(4.57)$ & \\
\hline
\end{tabular}

Table 1: Descriptive data of surface roughness before and after immersion into different solution for different materials $(n=10)$.

Shapiro-Wilk test was done to assess the normality of the data as a prerequisite prior to conduct one way ANOVA, the $p$ value $>0.05$, then one way ANOVA was done separately for each of restorative materials, the result showed the $\mathrm{p}$ value for each material was less than 0.05 which mean the restorative materials has significant changes after immersion in the juices. The $p$ value of the restorative materials after comparing among the fruit juices. This study showed for composite there was significant difference after comparing the immersion between tamarind and pineapple, 
mango and distilled water. There was also significant difference of glass ionomer cement in mango compared to pineapple, tamarind and distilled water. Same with resin modified glass ionomer cement whereby there was significant difference when compare between pineapple to mango, tamarind and distilled water.

\section{Discussion}

This study examined the effect of acidic beverages on the roughness of composite, glass ionomer cement and resin modified glass ionomer cement. Pineapple, mango and tamarind juices were selected because they were frequently consumed in Malaysia. The $\mathrm{pH}$ of the pineapple, mango and tamarind juices are 3.18, 3.11, and 3.00 respectively. This study focused on surface roughness as we want to get smooth surface of the restoration for better aesthetic, reduce plaque accumulation, to increase the longevity of the restoration in oral cavity and to reduce marginal deterioration that may cause secondary caries if present [19]. Stylus profilometer was used in this study as it gives quantitative measurement. It was also an established technique and more economical compared to Scanning Electron Microscope (SEM) and 3D scanning microscope [20]. Commercialised fruit juices were used as they were readily available and the $\mathrm{pH}$ can be controlled as it had undergone quality control and their ingredients are fixed as follow: for mango juice (F\&N Fruit Tree, Shah Alam, Malaysia) are mango juice, sugar and citric acid, for the tamarind juice (F\&N Fruit Tree, Shah Alam, Malaysia) are concentrated tamarind juice, ascorbic acid and salt, and finally for pineapple juice (F\&N Fruit Tree, Shah Alam, Malaysia) are pineapple juice, sugar and citric acid, as compare when using freshly prepared juices where we could not control the $\mathrm{pH}$. Moreover, people usually choose to buy fruit juices in the can instead of make it by themselves [21]. Generally, the surface roughness values of the tooth coloured restorative materials after immersion in the selected fruit juices were higher. This study accordance to study done by Rajavardhan et al., [22]. This study also confirmed the erosive potential of selected fruit juices that people should aware.

This study also showed that even though the acidic fruit juices have about the same $\mathrm{pH}$, the effect to the restorative materials were different. This may be because the acidity strength was not only depending on $\mathrm{pH}$ but also involved other factors such amount of acid available, buffering capacity, chelating function of the acid, titratable acidity, $\mathrm{pKa}$, temperature, and the concentration of acid $[1,23]$. As mentioned above, flavoured fruit juices consist of organic acid such as citric, maleic, and ascorbic acid which can contribute to the acidity but can also be used as modifying or buffering and flavouring agents [6]. In this study, composite showed higher mean changes in surface roughness compare to glass ionomer cement. It was supported by studies done by Rios D et al., in 2008 and Wongkhantee et al., in 2006, where they stated that composite had high wear rate due to acid attack to the resin causing softening of Bis GMA based polymers and leaching of TEGDMA. The resin matrix of the composite gets soften by acid and increased filler content in lower water absorption result in surface degradation. On the other hand, glass ionomer cement showed low wear rate may be because it had high fluoride content. However, the ability of fluoride release varies between different restoration materials and within brands. The optimum fluoride release related to matrices, setting mechanism of fluoride content and environment conditions $[1,24]$. This study was contradicted to study done by Daniela et al., Shabanian and Richards. Their study found that the glass ionomer cement had higher wear rate than composite. They explained that glass ionomer cement is more susceptible to the effect of low $\mathrm{pH}$ solution [24,25]. The differences in results between this study and previous studies were probably due to difference in methodology such as the immersion time, the chemical composition of the restorative materials. As a clinician, the result of this study might be applied in daily clinical session. We might encounter patient with the signs and symptoms of dental erosion and we can further ask for the causes and details. If the patient was taking the juices selected in this study, we can advised them to stop consuming the drinks to prevent further deterioration to their teeth. This study only done in acidic beverages and in short period of time which was one day due to time constrain, hence, the result might be not accurate, that is why further studies are recommended using different drinks with different $\mathrm{pH}$ to compare effect of acidic, alkaline and neutral $\mathrm{pH}$ beverages and immersed the samples in longer period of time as the time taken in this study may not represent the normal consumption pattern of acidic fruit drinks by patients. Studies besides surface roughness also can be proposed in the future. Example is the surface hardness, staining effect, temperature and other surface characteristic.

\section{Conclusion}

In conclusion, there was difference in surface roughness changes after immersion of the selected tooth coloured restorative materials in the selected fruit juices even though the $\mathrm{pH}$ of the beverages is about the same. It can be concluded that the selected fruit juices used in this study resulted in changes in surface roughness of the selected tooth coloured restorative materials, whereby the post immersion surface roughness was higher that pre- immersion surface roughness.

\section{References}

1. Wongkhantee S, Patanapiradej V, Maneenut C, Tantbirojn D (2006) Effect of acidic foods and drinks on surface hardness of enamel, dentine, and tooth-colored filling materials. J Dent 34: 214-220.

2. Satyajit S, Lutfun N (2007) Chemistry for Pharmacy Students: General, Organic and Natural Product Chemistry. John Wiley \& Sons Ltd, USA.

3. Mahoney EK, Kilpatrick NM (2003) Dental Erosion: Part 1. Aetiology and Prevalence of Dental Erosion. N Z Dent J 99: 33-41.

4. Zimmerli B, Strub M, Jeger F, Stadler O, Lussi A (2010) Composite materials: composition, properties and clinical applications. A literature review. Schweiz Monatsschr Zahnmed 120: 972-986.

5. El-Korashy DI, Mobarak EH, El-Korashyand DI (2006) Effect of cola drinks on surface roughness of some contemporary tooth-coloured restorative materials: A non-contact interferometric approach. Egypt Dent J 52: 895-899.

6. Kitchens M, Owens B (2007) Effect of carbonated beverages, coffee, sports and high energy drinks, and bottled water on the in vitro erosion characteristics of dental enamel. J Clin Pediatr Dent 31: 153-159.

7. Cairns AM, Watson M, Creanor SL, Foye RH (2002) The pH and 
Citation: Mustain SMB, Alkadhim AH, Fatah FA, Jaafar A (2017) Effect of Tropical Fruit Juices on Surface Roughness of Tooth Coloured Restorative Materials. J Dent Sci Res Ther 2017: 26-29.

titratable acidity of a range of diluting drinks and their erosive potentia effect on dental erosion. J Dent 30: 313-317.

8. Scheutzel P (1996) Etiology of dental erosion - intrinsic factors. Eur J Oral Sci 104: 178-190.

9. Devlin H, Bassiouny MA, Boston D (2006) Hardness of enamel exposed to Coca Cola and artificial saliva. J Oral Rehabil 33: 26-30.

10. Dincer B, Hazar S, Sen BH (2002) Scanning electron microscope study of the effects of soft drinks on etched and sealed enamel. Am J Orthod Dentofac Orthop 122: 135-141.

11. Turkun LS, Turkun M (2004) Effect of bleaching and repolishing procedures on coffee and tea stain removal from three anterior composite veneering materials. J Esthet Restor Dent 16: 290-301.

12. Tjan AH, Chan CA (1989) The polishability of posterior composites. J Prosthet Dent 61: 138-146.

13. Paravina RD, Roeder L, Lu H, Vogel K, Powers JM (2004) Effect of finishing and polishing procedures on surface roughness, gloss and colour or resin-based composites. Am J Dent 17: 262-266.

14. Han L, Okamoto A, Fukushima M, Okiji T (2008) Evaluation of flowable resin composite surfaces erode by acidic and alcoholic drinks. Dent mater J 27: 455-465.

15. Ferracane JL (2006) Is the wear of dental composites still a clinical concern? Is there still a need for in vitro wear simulating devices? Dent Mater 22: 689-692.

16. Yap AU, Tan SH, Wee SS, Lee CW, Lim EL, et al. (2001) Chemical degradation of composite restoratives. J Oral Rehabilitation 28 : 1015-1021.
17. Abu Bakr N, Han L, Okamoto A, Iwaku M (2000) Changes in the mechanical properties and surface texture of compomer immersed in various media. J Prosthet Dent 84: 444-452.

18. Wan Bakar WZ, McIntyre J (2008) Susceptibility of selected tooth coloured dental materials to damage by common erosive acids. Aust Dent J 53: 226-234.

19. Goyel P, Singh MG, Bansal R (2013) Comparative evaluation of erosive potential of different beverages on enamel and tooth coloured restorative materials: An in vitro study. J Pediatr dent 1: 58-62.

20. Pedrini D, Candido MS, Rodrigues AL (2003) Analysis of surface roughness of glass ionomer cements and compomer. J Oral Rehabil 30: 714-719.

21. Kimyai S, Savadi-Oskoee S, Ajami AA, Sadr A, Asdagh S (2011) Effect of three prophylaxis methods on surface roughness of giomer. Med Oral Patol Oral Cir buccal 16: 110-114.

22. Rajavardhan K, Sankar A, Kumar M, Kumar K, Pranitha K, et al. (2014) Erosive Potential of Cola and Orange Fruit Juice on Tooth Colored Restorative Materials. Ann Med Health Sci Res Suppl 3: 208-212.

23. Babu GK, Rai K, Hedge AH (2008) Pediatric liquid medicaments- Do they erode the teeth surface? An in vitro study: Part 1. J Clin Pediatr Dent 32: 189-194.

24. Rios D, Honorio HM, Francisconi LF, Magalhaes AC, de Andrade Moreira Machado MA, et al. (2008) In situ effect of on an erosive challenge on different restorative materials and on enamel adjacent to these materials. J Dent 36: 152-157.

25. Shabanian-Borojeni M, Richards LC (2002) In vitro wear of materials under loads and varying $\mathrm{pH}$. J Prosthet Dent 6: 650-656. 